\title{
İşletmelerin Ürün Kalitesi Etkinliğinin Analiz Edilmesi İçin Bulanık Veri Zarflama Analizi Yönteminin Kullanılması
}

\author{
The Using of Fuzzy Data Envelopment Analysis Method to \\ Analysis of Enterprises Product Quality Efficiency
}

\section{Prof. Dr. Onur Özveri - Dr. Muhammed Kabak}

Başvuru Tarihi: 18.05 .2017

Kabul Tarihi: 24.01.2018

\section{Öz}

Son 20 yılda üretim teknolojilerinde yaşanan gelişmeler ve üretilen ürünlerin küresel pazara sunulabilmesi, satın alınabilecek ürünlere ilişkin çok sayıda alternatife sahip olan müssterin beklentilerini artmıştır. Bu nedenle ürün kalitesinin önemi artmış ve ürün kalitesi tek boyutlu bir kavram olmaktan çıkarak, çok boyutlu bir kavram haline gelmiştir. Işletmelerin faaliyet gösterdikleri sektörde pazar payını artırması ve rekabet avantajı elde edebilmesi için, ürettikleri ürülerin kalitesinin, sektördeki rakiplerinin ürünlerine göre durumunu analiz etmeleri gereklidir. Belirli bir sektörde faaliyet gösteren işletmelerin ürün kalitesi bakımından değerlendirilmesi ve en iyi durumdaki işletmenin belirlenmesi için kullanılabilecek yöntemlerden bir tanesi "Bulanık veri zarflama analizi (BVZA)" yöntemidir. Bu çalışmada İstanbul, Ankara, İzmir, Kocaeli ve Kayseride faaliyet gösteren makine üretim işletmelerinin ürün kalitesi etkinlik analizi bulanı veri zarflama analizi yöntemi ile gerçekleştirilmiştir.

Anahtar Kelimeler: Ürün Kalitesi, Etkinlik Analizi, Bulanik Veri Zarflama Analizi

\begin{abstract}
Because of the progress on production technology in last two decades and presentation of manufacturing product into global market, customers which have a large number of affordable product alternatives, expectations increased. Therefore, importance of product quality incresed and product quality get beyond a single dimensional concept and it became a multi dimensional concept. It is neccesary to analysis quality of manufacturing products in comparison with their competitors so as to increase their market share and gain competition edge. Fuzzy data envelopment analysis method is one of the methods for using determine best enterprise in terms of product quality and assesing product quality of enterprises in business a certain sector. In this paper, analysis of product quality efficiency was implemented by fuzzy data envelopment analysis to machinery manufacturing sector in business enterprises in Istanbul, Izmir, Kocaeli, Ankara and Kayseri.
\end{abstract}

Keywords: Product Quality, Efficiency Analysis, Fuzzy Data Envelopment Analysis

Prof. Dr. Onur Özveri, Dokuz Eylül Üniversitesi İIBBF, onur.ozveri@deu.edu.tr Dr. Muhammed Kabak, Dokuz Eylül Üniversitesi İIBF, ahmetkabakdeu@gmail.com 


\section{Giriş}

Günümüzde teknoloji alanında yaşanan gelişmelerle birlikte ürün niceliği artmış, tüm dünyada her tür ürün çok kolay ve yaygın bir şekilde elde edilebilir hale gelmiştir. Satın alacakları ürünle ilgili çok sayıda alternatif seçme imkânına sahip olan müşteriler, ürünün beklentilerini ve belirlenen spesifikasyonları karşılamasını istemektedir. Müşterilerin satın alacakları ürün ve hizmetle ilgili beklentilerinin karşılanması söz konusu ürün ya da hizmetin kalitesi ile bağlantılıdır. Müşteri kitlesinin beklenti ve algılarının değişmesi işletmelerin kalite konusuna bakış açılarının değişmesine neden olmuştur. Günümüzde kalite tek boyutlu bir anlam ifade etmenin ötesine geçmiştir ve çok boyutlu olarak değerlendirilen bir kavram olarak ele alınmaktadır. Ürün ve hizmet kalitesi müşteri beklentilerinin ve belirlenmiş olan spesifikasyonların karşılanması amacıyla çok boyutlu olarak ele alınmaktadır. Ürün ve hizmet kalitesine ilişkin değerlendirmeler ve iyileştirme çalışmaları söz konusu ürün ve hizmet kalitesi boyutlarına göre gerçekleştirilmektedir.

Garvin (1984) ürün kalitesini; performans, uygunluk, güvenilirlik, hizmet görürlük, ek özellikler, dayanıkllık, estetik ve algılanan kalite olmak üzere 8 boyut olarak ele almıştır. Bu çalışmada endüstriyel makine üretim işletmelerinde ürün kalitesi etkinliği bulanık veri zarflama analizi modelleri ile analiz edilerek işletmelerin ürün kalitesi etkinlik değerlerine göre sıralanması amaçlanmıştır. Bu doğrultuda, ürünler ve sektörler için sübjektif değerlendirmelere göre farklılık gösteren ürün kalitesinin analiz edilmesi için uygun bir yöntem kullanılması amaçlanmıştır. Uygulanan yöntemle üretim işletmelerinin kendi sektörlerinde yer alan rakiplerinin ürünleri ve kendi ürünlerini değerlendirerek, ürün kalitesi bakımından sektörde bulundukları noktayı belirleme imkanı elde etmeleri mümkün olacaktır. Bu çalışmanın temel amacı Türkiye'de faaliyet gösteren işletmelerin ürettikleri ürünün kalitesini sektördeki rakiplerinin ürünlerine göre değerlendirmesine olanak sağlayacak bir yöntemin ortaya konulmasıdır.

\section{Ürün Kalitesinin Boyutları}

Ürün kalitesi, ürünün belirlenen spesifikasyonları karşılamasının ve ürün dizaynı ile belirlenen teknik koşulları sağlayıp sağlamadığının göstergesidir. Ürün kalitesi, temelde üretim ile ilgili olarak görülse de satış, servis ve dizayn gibi ürünle ilgili tüm süreçlerle ilişkilidir (Chorafas, 2013, s.4). Müşteri açısından ürün kalitesi üründen sağlanan, ürünün temel kullanım amacina uygun olan fiziksel ve fonksiyonel fayda ile ilgilidir. Bu nedenle ürün kalitesi kesin bir yargıya dayanmaz ve müşterinin satın alma kararından önce diğer ürünlerle yaptığı karşılaştırmalar sonucunda çeşitli boyutlar açsısından yaptığı değerlendirmelere dayalı olarak tanımlanır (Ackaradejruangsri, 2013, s.15). Literatürde yer alan çalışmalarda düşük ürün kalitesinin sonucu olarak işletme açısından ortaya çıkan maliyet grupları; önleme maliyetleri, değerlendirme maliyetleri, iç hata maliyetleri ve dış hata maliyetleri başlıkları altında incelenmiştir. Söz konusu başlıklar altında ele alınan maliyet kalemleri; hurda maliyetleri, yeniden işleme maliyetleri, ürün iade maliyetleri, üretimin kesintiye uğraması, ürünlerin geri çağrılma maliyetleri, ürünlerin yeniden muayene edilmesinin maliyetleri, garanti bakım maliyetleri şeklinde sıralanmıştır (Chiarihi, 2015, s.148; Harrington, 1999, s.222; Mahmood vd, 2014, s.298; Shukla ve Agrawal, 2012, s.1298).

Bazı çalışmalarda ürün kalitesi çok boyutlu bir konsept olarak, müşteri tarafından tanımlanan ve müşteri açısından değer ifade eden farklı kalite boyutlarına göre tanımlanmaktadır. Ürün kalitesinin boyutları ile ilgili literatürde üzerinde en fazla çalışma yapılan sınıflandırma Garvin (1984) tarafından geliştirilen ürün kalitesi boyutları sınıflandırmasıdır. Garvin ürün kalitesini; Performans, ek özellikler, güvenilirlik, standartlara uygunluk, dayanıklılık, hizmet görürlük, estetik ve algılanan kalite şeklinde 8 boyut olarak ele almıştır (Garvin, 1984, s.29). Performans, ürünü dizayn edenler tarafından belirlenen ve üretilme amacına ilişkin temel fonksiyonunu yerine getirmesi ile ilgili özellikleri ifade etmektedir (Kenyon ve Sen, 2015, s.173). Ek özellikler, ürünün temel fonksiyonunu destekleyen ikincil özellik ve unsurları, güvenilirlik ise bir ürünün dizayn aşamasında öngörülen kullanım süresinde fonksiyonunu istikrarlı bir şekilde yerine getirme eğilimidir (Kianpour vd. 2014, s.550). Uygunluk, ürünün dizayn özellikleri veya çalışmasına ilişkin özelliklerinin daha önceden belirlenen standartlara uygun olma durumunu ifade etmektedir. (Gildea, 1991, s.38). Dayanıklılık, teknik olarak bir ürünün fiziksel olarak işlevini yerine getiremez ve tamir edilemez hale gelmeden önce kullanım miktarıdır (Kianpour vd. 2014, s.551). Hizmet görürlük, ürünün arızalanması vb. durumlarda tamir bakım işlemlerinin hızı, yeterliliği ve bakım perso- 
nelinin müşteriye karşı tutumu ile ilgili kalite boyutudur (Garvin, 1984, s.32). Estetik boyutu subjektif yargılara dayalı olarak değerlendirilen kalite boyutlarından biridir. Kişilerin tercih ve öncelikleri estetik boyutunun değerlendirilmesinde belirleyicidir (Arnheiter ve Harren, 2006, s.88). Son olarak algilanan kalite, Müşteri gözünde ürüne ilişkin marka imajı ve reklamla oluşan kalite algısı ile ilgili boyuttur (Garvin, 1984, s.32).

\section{Bulanık Veri Zarflama Analizi}

Veri zarflama analizi (VZA), çok sayıda benzer girdi ile benzer çıtılar üreten birden fazla organizasyonel biriminin göreli etkinliğini ölçmeye yarayan, doğrusal programlama tabanlı bir yöntemdir. VZA, bir organizasyonel birimin mevcut kaynaklarını ne kadar verimli kullandığını ölçümler (Tütek vd, 2012s, s.223). VZA parametrik olmayan bir etkinlik ölçüm yöntemidir ve bu nedenle parametrik olmayan programlama olarak da ifade edilmektedir (Tarım, 2001, s.45). Çok sayıda farklı girdiye sahip olan, farklı ölçüm birimleri ile ölçülen girdi ve çıktılara sahip birimlerin etkinliği doğrusal programlama prensipleri temelinde VZA ile ölçümlenebilmektedir (Akyüz vd. 2015. s.51). VZA ile hesaplanan etkinlik skoru aşağ1daki şekilde ifade edilir (Bal, 2013, s.4).

$$
\text { Etkinlik }=\frac{\text { Ăgrlıklandırılmış Çıktılar Toplamı }}{\text { Ağırlıklandırılmış Girdiler Toplamı }}
$$

VZA yönteminin en önemli avantajlarından birisi etkin olmayan karar verme birimlerinin etkinliğe ulaşması için girdi ve çıktı değişkenlerini hangi oranda iyileştirmeleri gerektiğinin belirlenmesidir. $\mathrm{Bu}$ amaçla oluşturulan dual VZA modelinde yer alan $\lambda$ değişkeninin aldığı değere göre etkin olmayan karar verme birimleri için referans kümeleri belirlenmektedir. Etkin olmayan bir karar verme birimi için referans grubunda yer alan etkin karar verme birimlerinin girdi ve çıtı değişkenlerinin değerleri baz alınarak iyileştirme oranları hesaplanmaktadır. VZA yöntemi etkinlik analizi yapılan karar verme biriminin diğer karar birimlerine göre konumunu belirlemenin yanı sıra, etkin olmayan karar verme biriminin etkin olabilmesi için girdi ve çıktılarını ne ölçüde iyileştirmesi gerektiğini belirleme olanağ 1 da sağlamaktadır. Bu özelliğinden dolayı literatürde bazı çalışmalarda VZA yöntemi işletmelerin en iyi benchmarking partnerini seçmelerine yardımcı olan bir yöntem olarak da kullanılmıştır. VZA yönteminde farklı formlardaki modeller doğrusal programlama modeli şekline dönüştürülerek çözülebilmektedir. Ancak karar verme birimi ve girdi, çıktı sayısı arttıkça modeller daha karmaşı hale gelmekte ve uygulanması zorlaşmaktadır. Bu durumlar için VZA uygulamalarını kolaylaştırmak adına EMS, DEA Frontier, PIM DEA gibi programlar kullanılabilmektedir.

Veri zarflama analizi veri tabanlı bir etkinlik ölçüm yöntemi olduğu için yöntemde kullanılacak verilerin doğru olması ve kesin olarak bilinmesi gerekmektedir. Ancak pratikte bir karar verme biriminin göreli etkinliğinin ölçülebilmesi için kullanılacak girdi ve çıktıların değerleri her zaman tam, doğru olarak bilinememektedir. Buna benzer durumlarda karar verme birimlerinin etkinliklerinin ölçülebilmesi için "Bulanık veri zarflama analizi" (BVZA) modelleri geliştirilmiştir (Oruç vd. 2009, s.280). BVZA, girdi ve çıktılar açısından belirsizlik veya tam belirlenememe durumlarının söz konusu olduğu karar verme birimleri için göreli etkinlik ölçümü sağlar (Azadeh vd. 2010, s.824).

Bazı durumlarda karar verme birimlerinin girdi ve çıktılarının kesin değerleri ölçülemez. Hizmet kalitesi düzeyi, girdi kaynaklarının kalitesi, tatmin düzeyi vb. değişkenlere ilişkin veriler, tam değer olarak ölçülesi zor olan verilere örnek olarak gösterilebilir. Bu tür veriler bulanık mantık yaklaşımına uygun değişkenler olarak ifade edilir ve bulanık veri zarflama analizi etkinlik ölçümünde kullanılabilir (Agarwal, 2014, s.60). Bazı vakalarda ise değerlendirmeye tabi tutulan girdi ve çıktı değişkenleri "Daha iyi", "İyi", "Orta", "Kötü" gibi sıralı dilsel değerlerle ifade edilmektedir (Guo ve Tanaka, 2001, s.150). Bu ve benzeri durumlar için de bulanık veri zarflama analizinin kullanılması önerilmektedir (Marbini vd, 2010, s.1062). Bulanık veri zarflama analizinde kullanılan veriler; kesin değeri bilinmeyen veriler, alt ve üst sinır olarak belirlenmiş sınırlandırılmış veriler, büyüklük küçüklük şeklinde ifade edilen sıralı veriler olabilir (Despotis ve Smirlis, 2002, s.24). BVZA modelleri kullanılan verilerin türüne göre üç başlık halinde sinıflandırılır. İlk grup modeller; Sıralı ve kesin değeri bilinen veriler için BVZA modelleridir. İkinci grupta yer alan modeller; Sıralı, sınırlandırılmış ve kesin değeri bilinen veriler için BVZA modelleridir. Üçüncü grupta yer alan modeller ise; Sınırlandırılmış ve kesin değeri 
bilinen veriler için BVZA modelleri olarak ifade edilmektedir (Güngör ve Oruç, 2009, s.19). Bu çalışmada uygulamada kullanılacak olan Cook - Kress - Seiford modeli aşağıda kısaca açıklanmıştır.

\section{Cook - Kress - Seiford Modeli}

Cook - Kress - Seiford (1993) modeli ilk olarak s1ralı veriler için kullanılan bir BVZA modeli olarak uygulanmıştır. Daha sonra, 1996 yılında geliştirilerek sıralı ve kesin değeri bilinen veriler için uygulanan bir model haline getirilmiştir. Modelin amac1, hem kesin değeri bilinen kantitatif veriler, hem de sıralı kalitatif verilerin veri zarflama analizinde kullanılması olarak ifade edilmiştir (Cook vd. 1996, s.945). $s$ adet kesin değeri bilinen çıktı, $w$ adet sıralı çıktı, $m$ adet kesin değeri bilinen girdi ve $f$ adet sıralı girdiye sahip olan $z$. karar verme birimi varsayılsın. Söz konusu karar verme birimi için girdi odaklı Cook - Kress Seiford modeli aşağıdaki gibi oluşturulur (Oruç, 2008, s.67).

Amaç Fonksiyonu:

$$
\text { Maks } \sum_{r=1}^{s} u_{r} y_{r z}+\sum_{h=1}^{w} \sum_{l=1}^{L} u_{h}^{l} y_{h z}^{l}
$$

Kisitlar:

$$
\begin{gathered}
\sum_{r=1}^{s} v_{i} x_{i z}+\sum_{b=1}^{f} \sum_{l=1}^{L} v_{b}^{l} x_{b z}^{l}=1 \\
\sum_{r=1}^{s} u_{r} y_{r j}+\sum_{h=1}^{w} \sum_{l=1}^{L} u_{h}^{l} y_{h j}^{l}-\sum_{r=1}^{s} v_{i} x_{i j}+\sum_{b=1}^{f} \sum_{l=1}^{L} v_{b}^{l} x_{b j}^{l} \leq 0 \\
j=1 \ldots . n, \quad r=1 \ldots . s, \quad i=1 \ldots . m, h=1 \ldots w, b=1 \ldots f \\
u_{r}, v_{i} \geq \varepsilon, L \leq n
\end{gathered}
$$

En küçük sıralı veri $\delta\left(10^{-6}\right)$ dan büyük olmak üzere her h. çıktı için sıralı çıktılar arasındaki fark $>0$

En küçük sıralı veri $\delta\left(10^{-6}\right)$ dan büyük olmak üzere her b. girdi için sıralı girdiler arasındaki fark $>0$

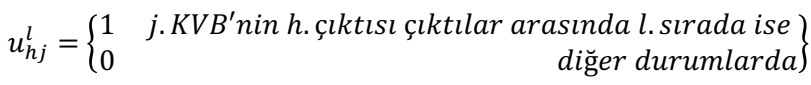

$$
\begin{aligned}
& v_{b j}^{l}=\left\{\begin{array}{rr}
1 & j . K V B^{\prime} \text { nin b. girdisi girdiler arasında l. sırada ise } \\
0 & \text { diğer durumlarda }
\end{array}\right\}
\end{aligned}
$$

Yukarıda verilmiş olan modelde yer alan;

$u_{i}$ : Kesin değeri bilinen $i$. çıktının ağırlık değerini,

$v_{i}$ : Kesin değeri bilinen $i$. girdinin ağırlık değerini,

$u_{h j}^{l}: j$. karar verme birimi için $h$. sıralı çıktının ağırlık değerini,

$v_{b j}^{l}: \mathrm{j}$. karar verme birimi için $b$. sıralı girdinin ağırlık değerini ifade etmektedir.

Modelde yer alan sıralı çıktıların sıra numaraları $L \ni l$ şeklinde bir küme oluşturur. Örnek olarak sıralı bir girdi veya çıktı verisi için çok önemli (1), önemli (2), önemsiz (3) ve çok önemsiz (4) sıralaması verilsin.
$\mathrm{Bu}$ durumda $\mathrm{L}$ kümesi $\mathrm{L}=\{1,2,3,4\}$ şeklinde oluşur. Birden fazla karar verme biriminin aynı sıra değerini (l) alması mümkün olduğu için modele $L \leq n$ kısıtı eklenmiştir (Oruç, 2008, s.68). 


\section{Uygulama}

$\mathrm{Bu}$ çalışmada, Garvin tarafından geliştirilmiş olan ürün kalitesi boyutlarına bağlı olarak, makine imalat sektörü işletmelerinin ürün kalitesi etkinliği analiz edilecektir. Bu amaçla, bulanık veri zarflama analizi yöntemi kullanılmıştır. Bulanık veri zarflama analizi için girdi ve çıtı değişken değerlerinin belirlenmesi amacıyla makine imalat sektörü işletmelerinin kendi ürünlerini, ürün kalitesi boyutları ve ürün kalitesinin düşük olmasının sonuçları bakımından değerlendirmelerine olanak sağlayan bir ölçek kullanılmıştır. Ölçek 3 grup sorudan oluşmaktadır. Birinci grupta, işletmelerin ürettikleri ürünlerin genel kalite seviyelerini değerlendirmelerini amaçlayan 3 soru yer almaktadır. İkinci grupta, endüstriyel makine üretim işletmelerinin ürün kalitelerini değerlendirmelerini sağlamak amacıyla ürün kalitesi boyutlarına ilişkin 22 soru yer almaktadır. Üçüncü grupta ise, ürün kalitesi- nin düşük olmasının sonuçları ile ilgili değerlendirme sorularına yer verilmiştir. İlk grupta yer alan sorular literatürden elde edilen bilgiler ışığında geliştirilmiştir. İkinci grupta yer alan sorular Kianpour ve diğerleri (2014) tarafından yapılan çalışmada kullanılan ölçek uyarlanarak elde edilmiştir. Üçüncü grupta yer alan sorular ise, kalitesizlik maliyeti ile ilgili literatürde yer alan çalışmalardan elde edilen bilgilere dayalı olarak hazırlanmıştır. Kullanılan ölçeğe ilişkin apılan açıkyayıcı faktör analizi sonuçlarına göre, ölçekte yer alan yirmi dokuz değişkenden altı tanesi çapraz faktör yükü sorunu nedeniye analiz dışı bırakılmıştır. Faktör analizi sonucuna göre ürün kalitesi boyutlar1, "Yeniden İşleme" ve "Ürün iadesi" boyutları için ayrı ayrı yapılan güvenilirlik analizi sonuçlarına göre tüm faktörlere ilişkin güvenilirlik değerleri Tablo 1'de görüldüğü gibi kabul edilebilirlik sınırı olarak kabul edilen 0.60 değerinin üzerinde çıkmıştır.

Tablo 1. Ölçekte Yer Alan Faktörlere İlişkin Güvenilirlik Analizi Sonuçları

\begin{tabular}{|c|c|c|c|c|c|c|c|c|c|c|}
\hline FAKTÖRLER & PER. & E. ÖZ. & GÜV. & UYG. & DAY. & H. GÖR. & EST. & A. KAL & Ü. İAD. & Y .ंडș. \\
\hline $\begin{array}{c}\text { GÜVENILÍRLIK } \\
\text { KATSAYISI }\end{array}$ & 0,791 & 0,611 & 0,867 & 0,807 & 0,782 & 0,631 & 0,75 & 0,645 & 0,922 & 0,656 \\
\hline
\end{tabular}

Geliştirilen ölçekte yer alan 31 sorudan 23 tanesi için, ölçek geliştirme tekniklerinden "Sürekli bir doğru üzerinde fark belirtme ölçeği” tekniği kullanılmıştır. Sürekli bir doğru üzerinde fark belirtme tekniği genelde $13 \mathrm{~cm}$ olan ve iki yanında uç alternatifler olan, bir doğru üzerine işaret koyma esasına göre uygulanmaktadır. Değerlendirme sonuçları doğru üzerine yapılan işaretlemelerin uçlara uzaklığı ölçülerek belirlenir (Özdemir, 2016, s.69). Söz konusu ölçek geliştirme tekniğinin tercih edilmesinin nedeni, beşli ölçeğe göre daha objektif ve doğru değerlendirme yapılmasına olanak sağlamaktır. Ürün kalitesi boyutlarından hizmet görürlük, estetik ve algılanan kalite boyutları, birinci bölümde sübjektif yargılara dayalı olarak değerlendirilen ve somut sayısal değerlendirme yapılması diğer boyutlara göre daha zor olan boyutlar olarak ifade edilmiştir. Bu nedenle söz konusu 3 ürün kalitesi boyutuna ilişkin belirlenen 8 soruda değerlendirme dilsel değişkenlere göre yapılmıştır. Ölçekte yer alan altı soruda verilen ifadeye göre cevaplayıcılardan, "Çok Kötü", "Kötü" Orta Derece", "İyi" ve "Çok İyi" seçeneklerinden birini tercih etmeleri istenmiştir. Son 2 soru ise; verilen ifadeye göre
"Çok düşük", "Düşük", "Orta Derece", "Yüksek” ve "Çok Yüksek" seçeneklerinden birisi tercih edilecek şekilde hazırlanmıştır.

Ölçekten elde edilen veriler kullanılarak BVZA yöntemi ile endüstriyel makine üreticisi işletmeler için ürün kalitesi etkinlik skorları hesaplanmıştır. Bulanık veri zarflama analizi sonucunda etkin olarak bulunan, yani etkinlik skoru bir olan işletmelerin kendi içlerinde sıralanması için süper etkinlik analizi yapılmıştır. Süper etkinlik analizi sonucunda elde edilen etkinlik değerleri kullanılarak, işletmeler ürün kalitesi etkinliği bakımından sıralanmıştır. Ürün kalitesi boyutları hem objektif kriterlere dayalı olarak değerlendirilebilen, hem de sübjektif yargılara göre değerlendirilebilen boyutlar içermektedir. Ürün kalitesi boyutlarından hizmet görürlük, estetik ve algılanan kalite boyutları,kesin değeri bilinen sıralı dilsel değişkenler kullanılarak değerlendirilirken diğer ürün kalitesi boyutları kesin değeri bilinen sayısal değişkenlerle değerlendirilmiştir. Bu nedenle göreli etkinlik analizi, literatürde kesin değeri bilinen ve sıralı değişkenler için uygulanan tek BVZA modeli olan Cook - Kress - 
Seiford (CKS) modeli kullanılarak yapılmıştır. Cook - Kress - Seiford modeli sıralı ve kesin değeri bilinen veriler için uygulanan girdi odaklı CCR model formunda bir BVZA modelidir. Bu nedenle bulanik etkinlik analizi girdi okdalı olarak gerçekleştirilmiştir. Bu nedenle "Hizmet görürlük", "Estetik" ve "Algılanan kalite" boyutları ile ilgili faktör skorları sıralı veriler şeklinde kullanılmıştır. Ayrıca girdi odaklı CCR model kullanılarak da etkinlik analizi yapılmış iki modelle elde edilen sonuçlar karşılaştırılmıştır.

Çalışmanın temel amacı işletmelerin ürettikleri ürünlerin kalitesi bakımından rakiplerine göre durularını analiz etmelerine olanak sağlayan bir yöntem ortaya koymaktır. Bu amaçla göreli ürün kalitesi etkinlik analizi için ürün kalitesi boyutları ile ilgili elde edilen sonuçlar, BVZA yönteminde çıktı olarak kullanılmıştır. Ürün kalitesi ile ilgili göreli etkinlik analizinin girdi değişkenleri olarak ise, ürün kalitesinin düşük olmasının işletme açısından sonuçları olarak ele alınan "Yeniden ișleme" ve "Ürün iade" faktörleri ele alınmıștır. Ürün kalitesi boyutları literatürde ürün kalitesini belirleyen temel faktörler olarak ele alındığ 1 için göreli etkinlik analizi için çıktı değişkenler olarak ele alınmıştır. Girdi değişkeni olarak düşük ürün kalitesinin sonuçlarının tercih edilmesinin en önemli nedeni, son dönemde literatürde ürün kalitesi üzerine yapılan çalışmaların önemli bir kısmında, düşük ürün kalitesinin sonuçları üzerinde yoğun bir şekilde durulmasıdır. Literatürde ürün kalitesinin düşük olmasının sonucu olarak, tamir bakım maliyetleri, hurda maliyetleri, kalite kontrol maliyetleri vb. gibi çok sayıda kalitesizlik maliyeti kalemi ifade edilmektedir. Ancak, söz konusu kalitesizlik maliyetleri düşük ürün kalitesi ile bağlantılı olduğu kadar, müşterinin ürünü uygun kullanma durumu, üretim teknolojilerinde yaşanan arızalar vb. başka etkenlerle bağlantılı olarak da ortaya çıkabilmektedir. Bu nedenle, göreli etkinlik analizinde direkt olarak ürün kalitesinin düşük olması ile bağlantılı olarak değerlendirilen "Ürün iadesi" ve "Yeniden İşleme" faktörleri seçilmiştir (Harrington, 1999, s. 222; Mahmood vd. 2014, s. 298).

Ürün kalitesi göreli etkinlik analizi için, endüstriyel makine üretim işletmeleri arasından İstanbul, Kocaeli, İzmir, Ankara ve Kayseride faaliyet gösteren 30 işletme etkinlik analizine dahil edilmiştir. Söz konusu 30 işletme ulusal çapta faaliyet yürüten sanayici ve iş adamları dernekleri ile irtibata geçilerek, sektörde faaliyet gösteren üyelerinin bilgileri temin edilmek sureti ile uygulamaya dahil edilmiştir. Göreli etkinlik analizine az sayıda karar verme biriminin dahil edilmesi etkin çıkan karar verme birimi sayısının fazla olmasına sebep olmaktadır. Bu nedenle, literatürde etkinlik analizine dahil edilecek minimum karar verme birimi sayıları belirlenmiştir. Boussofiane (1991) çalışmanın güvenilir sonuçlara ulaşması için karar verme birimi sayısının $m$ girdi sayısını, $n$ çıktı sayısını ifade edecek şekilde en az $m+n+1$ tane olması gerektiğini belirtmiştir (Boussofiane vd, 1991, s.3). Dyson ve diğerleri (2001) $m$ girdi sayısı, $n$ çıktı sayısı olacak şekilde en az $2 m+n$ sayısı kadar olması gerektiğini iddia etmiştir (Dyson vd. 2001, s.248). Analize dahil edilen karar verme birimi sayısının yüksek olması da etkinlik analizi sonucunu etkilemekte ve etkin karar verme birimi sayısının artmasına neden olmaktadır. Göreli etkinlik analizi için kullanılacak çıktı değişken sayısı 8, girdi değişken sayısı 2'dir. Buna göre; yukarıdaki görüşler göz önüne alınarak, uygulamaya dahil edilen işletme sayısı etkinlik analizi yapılan karar verme birimi sayısı bakımından verilen minimum değerlerin üzerinde olacak ve etkinlik sonuçlarını etkilemeyecek şekilde 30 olarak belirlenmiştir. Ayrıca veri zarflama analizi ile göreli etkinlik analizine dahil edilen karar verme birimlerinin homojen büyüklükte olması gereklidir (Tütek vd. 2012, s. 224). Bu nedenle uygulamaya dahil edilen 30 işletme işgücü ve ciro olarak birbirine yakın büyüklükte işletmeler arasından seçilmiştir.

\section{Bulgular}

Cook - Kress - Seiford modeli üçüncü bölümde de ifade edildiği gibi kesin değeri bilinen ve sıralı veriler için uygulanan girdi odaklı CCR formunda bir BVZA modelidir. Söz konusu modelle göreli etkinlik analizi yapmak için ilk olarak girdi ve çıktı değişkenlerin faktör skorları belirlenmiştir. Bu amaçla, nicel değerlendirme yapılan performans, uygunluk, ek özellikler, dayanıklılık, güvenilirlik, yeniden işleme ve ürün iade boyutlarına ilişkin faktör skorları, faktörlere bağlı değişkenlerin aritmetik ortalamaları alınarak hesaplanmıştır. Dilsel değişkenlerle değerlendirme yapılan hizmet görürlük, estetik ve algılanan kalite boyutları için faktör skorlarının elde edilmesi için dilsel değişkenler tek bir değere dönüştürülerek sıralı veriler şekline getirilmiștir. Hizmet görürlük boyutu 3 değişken, estetik ve algılanan kalite boyutları ise 
ikişer değişkenden oluşmaktadır. Söz konusu boyutlara ilișkin tek bir faktör skorunun hesaplanması için değişkenlerin aldığı değerler için alt sınır ve üst sınır belirlenerek bulanıklaştırma işlemi uygulanmış ve değerlerin üyelik fonksiyonuna göre üyelik derecelerine dönüştürülmüştür. Bunun için ilk aşamada dilsel değişkenlere karşılık gelen sayısal değerler Tablo 2'de görüldügü gibi belirlenmiştir.

Tablo 2. Dilsel Değişkenler ve Karşılık Gelen Sayısal Değerler

\begin{tabular}{|c|c|}
\hline DíLSEL İFADE & SAYISAL KARŞILIK \\
\hline Çok Kötü, Çok Az & 1 \\
\hline Kötü, Az & 2 \\
\hline Orta Derece & 3 \\
\hline İyi, Yüksek & 4 \\
\hline Çok İyi, Çok Yüksek & 5 \\
\hline
\end{tabular}

Verilerin bulanıklaştırılması için Şekil 1'de grafiği verilmiş olan monotonik artan üyelik fonksiyonu tercih edilmiştir (Oruç, 2008, s. 63). Monotonik artan üyelik fonksiyonun matematiksel gösterimi aşağıda verilmiştir.

$$
\left\{\begin{array}{cc}
1 & x \geq U \\
\frac{x-l}{u-l} & L<x<U \\
0 & x \leq L
\end{array}\right\}
$$

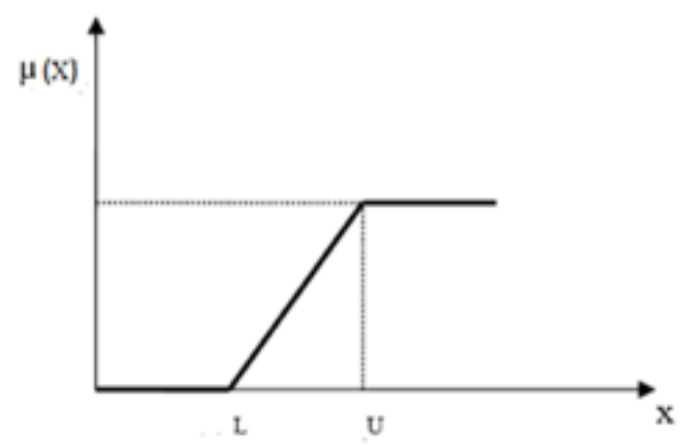

Şekil 1. Monotonik Artan Üyelik Fonksiyonu

Sonraki adımda ise üyelik dereceleri olarak ifade edilen değerler ağırlıklı ortalama yöntemi ile durulaştırılarak tek bir değere dönüştürülmüştür. Birden çok değer alan dilsel değişkenlerin tek bir sayısal değere dönüştürülmesinden sonra elde edilen durulaştırılmış çıktı değişken değerleri, Tablo 3'de yer alan aralıklar baz alınarak tekrar dilsel değişkenlere dönüştürülmüştür.
Tablo 3. Durulaştırılmış Değer Aralıkları ve Karşılık Gelen Dilsel Değişkenler

\begin{tabular}{|c|c|}
\hline ARALIK & DİLSEL DEĞİŞKEN \\
\hline $0,50 \leq x<1,5$ & Çok Kötü, Çok Az \\
\hline $1,50 \leq x<2,5$ & Kötü, Az \\
\hline $2,50 \leq x<3,5$ & Orta Derece \\
\hline $3,50 \leq x<4,5$ & İyi, Yüksek \\
\hline $4,50 \leq x \leq 5$ & Çok İyi, Çok Yüksek \\
\hline
\end{tabular}

Örnek olarak, ürün kalitesi etkinliği analiz edilecek olan birinci işletme için hizmet görürlük boyutunun değerlendirilmesine ilişkin 3 değişkenden elde edilen 3 dilsel ifade aşağıdaki şekilde tek bir dilsel değişkene dönüştürülür. Birinci karar verme birimi için hizmet görürlük boyutuna bağlı 3 değişkene ilişkin anketten elde edilen değerlendirme sonuçları, HIZMET_1 değişkeni için “ORTA DERECE”, HIZMET_2 değişkeni “IYII” ve HIZMET_3 değişkeni için “ORTA DERECE” şeklindedir. Söz konusu dilsel ifadelere karşılık gelen sayısal değerler sırasıyla 3, 4 ve 3 olarak belirlenmiştir. Hizmet görürlük boyutuna bağlı 3 değişkenin alabileceği en düşük değer "Çok Kötü”, en yüksek değer ise "Çok İyi” ifadesidir. Hizmet görürlük boyutuna bağlı değişkenler yukarıda da ifade edildiği gibi 3,4 ve 3 değerini almıştır. Monotonik artan üyelik fonksiyonuna göre üç değeri için üyelik derecesi " 0,50 ”, dört değeri için üyelik derecesi “ 0,75 ” olarak elde edilmiştir. Ağırlık merkezi yöntemine göre söz konusu üyelik derecesine sahip üç değişken aşağıdaki şekilde durulaştırılarak tek bir değişkene dönüştürülür.

$\frac{\sum \mu(\tilde{x}) \tilde{x}}{\sum \mu(\tilde{x}) \tilde{x}}=\frac{0,5 *(3)+0,75 *(4)+0,5 *(3)}{0,5+0,75+0,5}=3,42$ 
Tablo 2'de yer alan değer aralıklarına göre hizmet görürlük boyutu için 3,42 değerine karşllık gelen dilsel değişken "ORTA DERECE” ifadesidir. Yukarıda ör- nek verilen işlemle hizmet görürlük boyutunun değerlendirildiği 3 dilsel ifade tek bir dilsel değişkene dönüştürülmüştür.

Tablo 4. Dilsel Değişken Değerlendirme Skorları ve Çıktı Değişken Değerleri

\begin{tabular}{|c|c|c|c|c|c|c|}
\hline KVB & $\begin{array}{l}\text { DEĞİŞKEN } \\
\text { SKORLARI } \\
\end{array}$ & Híz. G. & $\begin{array}{l}\text { DEĞİŞKEN } \\
\text { SKORLARI } \\
\end{array}$ & ESTETIK & $\begin{array}{l}\text { DEĞİŞKEN } \\
\text { SKORLARI } \\
\end{array}$ & AL. KALITTE \\
\hline 1 & $3,4,3$ & ORTA DERECE & 3,3 & ORTA DERECE & 3,3 & ORTA DERECE \\
\hline 2 & $4,3,3$ & ORTA DERECE & 3,5 & İYİ & 3,4 & İẎ̇ \\
\hline 3 & $5,4,5$ & ÇOK İYİ & 4,4 & İYİ & 4,4 & IYİ \\
\hline 4 & $3,5,3$ & İYİ & 3,4 & İYİ & 4,4 & İYİ \\
\hline 5 & $4,4,4$ & İYİ & 4,4 & İYİ & 3,4 & İYİ \\
\hline 6 & $3,4,4$ & İYİ & 3,3 & ORTA DERECE & 2,3 & ORTA DERECE \\
\hline 7 & $4,5,4$ & İYİ & 4,4 & İYI & 4,4 & İYİ \\
\hline 8 & $3,3,4$ & ORTA DERECE & 4,4 & İYं & 3,4 & İYI \\
\hline 9 & $3,4,4$ & İYİ & 3,3 & ORTA DERECE & 4,4 & İẎ \\
\hline 10 & $3,4,4$ & İYİ & 4,4 & İYİ & 4,5 & ÇOK İYI \\
\hline 11 & $4,4,4$ & ÇOK İYİ & 4,4 & İẎ & 3,4 & İYİ \\
\hline 12 & $4,4,5$ & İẎ & 5,4 & ÇOK İẎ & 3,4 & İẎ் \\
\hline 13 & $4,4,4$ & İẎ & 3,2 & ORTA DERECE & 3,4 & İẎ \\
\hline 14 & $4,4,5$ & İYİ & 4,4 & İYİ & 4,4 & İYİ \\
\hline 15 & $4,4,5$ & İYİ & 3,4 & İẎ & 3,4 & İẎ \\
\hline 16 & $5,5,5$ & ÇOK IYİ & 4,4 & İẎ & 4,5 & ÇOK IYİ \\
\hline 17 & $3,4,3$ & ORTA DERECE & 4,4 & İYİ & 3,4 & İYİ \\
\hline 18 & $3,4,3$ & ORTA DERECE & 4,4 & İYİ & 4,3 & İYİ \\
\hline 19 & $4,4,4$ & IYİ & 4,4 & İẎ & 2,4 & İẎ \\
\hline 20 & $4,4,4$ & İYİ & 4,5 & ÇOK IYẎ & 4,4 & IYİ \\
\hline 21 & $4,5,4$ & İYİ & 5,5 & ÇOK İẎ & 5,5 & ÇOK İYİ \\
\hline 22 & $4,5,5$ & ÇOK IYYİ & 3,4 & İYİ & 4,5 & ÇOK İYI \\
\hline 23 & $4,5,5$ & ÇOK İYİ & 4,3 & İYİ & 4,3 & İYİ \\
\hline 24 & $5,4,5$ & ÇOK IYYI & 4,4 & İYI & 4,4 & İYİ \\
\hline 25 & $4,4,4$ & İYİ & 4,3 & İYİ & 3,5 & İYİ \\
\hline 26 & $4,5,3$ & İYİ & 4,4 & İYİ & 3,3 & ORTA DERECE \\
\hline 27 & $3,4,4$ & İYİ & 4,4 & İẎ & 4,4 & İYİ \\
\hline 28 & $4,4,4$ & İYİ & 4,4 & İYİ & 3,4 & İYİ \\
\hline 29 & $4,4,4$ & İYİ & 4,4 & IYİ & 4,4 & İẎ் \\
\hline 30 & $3,4,3$ & ORTA DERECE & 4,4 & İYİ & 3,4 & İYİ \\
\hline
\end{tabular}

Tablo 4'de "Hizmet görürlük", "Estetik" ve "Algılanan kalite" boyutlarına bağlı değișenlerin aldığ 1 değerlerin sayısal karşılıkları ve durulaştırma sonucunda boyut için elde edilen dilsel değişken değerleri verilmiştir. Tablo 3'de yer alan "Hizmet görürlük", "Estetik" ve "Algılanan kalite" boyutlarına ilişkin dilsel değerlendirme sonuçlarının bulanık veri zarflama analizi modellerinde çıktı skorları olarak kullanılabilmesi için sıralı değişkenler șekline dönüştürülmesi gerekir. Tablo 5'de dilsel değişkenlerin sıralı verilere dönüştürülmesi sonucu elde edilen çıktı değerleri yer almaktadır. 


\section{Tablo 5. Bulanık Veri Zarflama Analizi Çıktı Değişken Değerleri}

\begin{tabular}{|c|c|c|c|c|c|c|c|c|}
\hline KVB & PER. & UYG. & DAY. & EK Ö. & GÜV. & HİZ. G. & EST. & AL. KA. \\
\hline 1 & 10,50 & 10,45 & 8,20 & 7,40 & 8,70 & $Y_{6,1}<Y_{6,4}$ & $Y_{7,1}<Y_{7,2}$ & $Y_{8,1}<Y_{8,2}$ \\
\hline 2 & 11,25 & 11,35 & 10,30 & 8,90 & 9,90 & $Y_{6,2}=Y_{6,1}$ & $Y_{7,2}<Y_{7,12}$ & $Y_{8,2}<Y_{8,10}$ \\
\hline 3 & 11,25 & 11,20 & 10,80 & 10,05 & 10,60 & $Y_{6,3}$ & $Y_{7,3}=Y_{7,2}$ & $Y_{8,3}=Y_{8,2}$ \\
\hline 4 & 10,25 & 10,15 & 7,95 & 8,45 & 9,25 & $Y_{6,4}<Y_{6,1}$ & $Y_{7,4}=Y_{7,2}$ & $Y_{8,4}=Y_{8,2}$ \\
\hline 5 & 11,55 & 11,80 & 9,95 & 8,70 & 9,95 & $Y_{6,5}=Y_{6,4}$ & $Y_{7,4}=Y_{7,2}$ & $Y_{8,5}=Y_{8,2}$ \\
\hline 6 & 10,95 & 10,90 & 7,85 & 7,40 & 8,45 & $Y_{6,6}=Y_{6,4}$ & $Y_{7,6}=Y_{7,1}$ & $Y_{8,6}=Y_{8,1}$ \\
\hline 7 & 12,25 & 12,50 & 11,25 & 9,45 & 10,50 & $Y_{6,7}=Y_{6,4}$ & $Y_{7,7}=Y_{7,2}$ & $Y_{8,7}=Y_{8,2}$ \\
\hline 8 & 9,85 & 10,50 & 8,65 & 8,90 & 9,30 & $Y_{6,8}=Y_{6,1}$ & $Y_{7,8}=Y_{7,2}$ & $Y_{8,8}=Y_{8,2}$ \\
\hline 9 & 10,45 & 10,95 & 8,40 & 9,30 & 9,40 & $Y_{6,9}=Y_{6,4}$ & $Y_{7,9}=Y_{7,1}$ & $Y_{8,9}=Y_{8,2}$ \\
\hline 10 & 11,35 & 11,75 & 8,70 & 8,90 & 9,55 & $Y_{6,10}=Y_{6,4}$ & $Y_{7,10}=Y_{7,2}$ & $Y_{8,10}$ \\
\hline 11 & 10,50 & 10,90 & 8,90 & 9,55 & 9,60 & $Y_{6,11}=Y_{6,3}$ & $Y_{7,11}=Y_{7,2}$ & $Y_{8,11}=Y_{8,2}$ \\
\hline 12 & 12,10 & 12,50 & 11,35 & 9,75 & 10,75 & $Y_{6,12}=Y_{6,4}$ & $Y_{7,12}$ & $Y_{8,12}=Y_{8,2}$ \\
\hline 13 & 10,80 & 10,95 & 8,55 & 9,45 & 9,10 & $Y_{6,13}=Y_{6,4}$ & $Y_{7,13}=Y_{7,1}$ & $Y_{8,13}=Y_{8,2}$ \\
\hline 14 & 10,40 & 11,60 & 10,05 & 9,80 & 9,90 & $Y_{6,14}=Y_{6,4}$ & $Y_{7,14}=Y_{7,2}$ & $Y_{8,14}=Y_{8,2}$ \\
\hline 15 & 10,95 & 11,15 & 9,60 & 8,45 & 9,95 & $Y_{6,15}=Y_{6,4}$ & $Y_{7,15}=Y_{7,2}$ & $Y_{8,15}=Y_{8,2}$ \\
\hline 16 & 12,20 & 12,65 & 11,95 & 9,80 & 11,95 & $Y_{6,16}=Y_{6,3}$ & $Y_{7,16}=Y_{7,2}$ & $Y_{8,16}=Y_{8,10}$ \\
\hline 17 & 11,85 & 11,90 & 10,85 & 9,25 & 10,20 & $Y_{6,17}=Y_{6,1}$ & $Y_{7,17}=Y_{7,2}$ & $Y_{8,17}=Y_{8,2}$ \\
\hline 18 & 11,05 & 11,60 & 8,75 & 9,05 & 9,25 & $Y_{6,18}=Y_{6,1}$ & $Y_{7,18}=Y_{7,2}$ & $Y_{8,18}=Y_{8,2}$ \\
\hline 19 & 8,60 & 10,70 & 8,55 & 7,30 & 8,90 & $Y_{6,19}=Y_{6,4}$ & $Y_{7,19}=Y_{7,2}$ & $Y_{8,19}=Y_{8,2}$ \\
\hline 20 & 12,20 & 12,15 & 11,25 & 10,10 & 11,60 & $Y_{6,20}=Y_{6,4}$ & $Y_{7,20}=Y_{7,12}$ & $Y_{8,20}=Y_{8,2}$ \\
\hline 21 & 9,25 & 10,35 & 9,15 & 9,00 & 9,40 & $Y_{6,21}=Y_{6,4}$ & $Y_{7,21}=Y_{7,12}$ & $Y_{8,21}=Y_{8,10}$ \\
\hline 22 & 11,30 & 7,85 & 10,50 & 6,05 & 10,15 & $Y_{6,22}=Y_{6,3}$ & $Y_{7,22}=Y_{7,2}$ & $Y_{8,22}=Y_{8,10}$ \\
\hline 23 & 9,95 & 9,70 & 9,50 & 9,55 & 11,85 & $Y_{6,23}=Y_{6,3}$ & $Y_{7,23}=Y_{7,2}$ & $Y_{8,23}=Y_{8,2}$ \\
\hline 24 & 8,45 & 7,80 & 9,30 & 8,45 & 9,65 & $Y_{6,24}=Y_{6,3}$ & $Y_{7,24}=Y_{7,2}$ & $Y_{8,24}=Y_{8,2}$ \\
\hline 25 & 9,60 & 8,40 & 8,15 & 4,85 & 7,75 & $Y_{6,25}=Y_{6,4}$ & $Y_{7,25}=Y_{7,2}$ & $Y_{8,25}=Y_{8,2}$ \\
\hline 26 & 6,35 & 9,20 & 8,05 & 8,45 & 6,65 & $Y_{6,26}=Y_{6,4}$ & $Y_{7,26}=Y_{7,2}$ & $Y_{8,26}=Y_{8,1}$ \\
\hline 27 & 12,30 & 7,80 & 6,90 & 5,60 & 6,05 & $Y_{6,27}=Y_{6,4}$ & $Y_{7,27}=Y_{7,2}$ & $Y_{8,27}=Y_{8,2}$ \\
\hline 28 & 10,50 & 10,20 & 9,95 & 10,10 & 10,20 & $Y_{6,28}=Y_{6,4}$ & $Y_{7,28}=Y_{7,2}$ & $Y_{8,28}=Y_{8,2}$ \\
\hline 29 & 10,10 & 10,00 & 9,45 & 9,65 & 9,35 & $Y_{6,29}=Y_{6,4}$ & $Y_{7,29}=Y_{7,2}$ & $Y_{8,29}=Y_{8,2}$ \\
\hline 30 & 9,95 & 9,85 & 8,80 & 9,50 & 9,05 & $Y_{6,30}=Y_{6,1}$ & $Y_{7,30}=Y_{7,2}$ & $Y_{8,30}=Y_{8,2}$ \\
\hline
\end{tabular}

BVZA için çıktı değişkenlerinin değerinin belirlenmesinden sonra, düşük ürün kalitesi sonuçları olarak etkinlik analizinde girdi değișkenler olarak ele alınan Yeniden işleme ve Ürün iade değişkenlerinin ortala- maları alınarak girdi değişkenlerin değerleri belirlenmiștir. Tablo 6'da girdi değişkenlere ilişkin girdi değişkenlerinin skorları verilmiştir. 
Tablo 6. Bulanık Veri Zarflama Analizi Girdi Değişken

\section{Değerleri}

\begin{tabular}{|c|c|c|}
\hline KVB & YENIDEN İŞLEM & ÜRÜN İADE \\
\hline 1 & 3,60 & 2,77 \\
\hline 2 & 3,25 & 2,03 \\
\hline 3 & 2,25 & 2,13 \\
\hline 4 & 3,70 & 3,23 \\
\hline 5 & 3,20 & 2,70 \\
\hline 6 & 3,35 & 2,27 \\
\hline 7 & 3,20 & 1,53 \\
\hline 8 & 3,00 & 2,90 \\
\hline 9 & 3,00 & 2,97 \\
\hline 10 & 3,10 & 2,43 \\
\hline 11 & 2,90 & 2,90 \\
\hline 12 & 2,95 & 1,90 \\
\hline 13 & 3,35 & 3,03 \\
\hline 14 & 3,30 & 2,97 \\
\hline 15 & 3,55 & 2,90 \\
\hline 16 & 1,85 & 1,07 \\
\hline 17 & 3,05 & 1,70 \\
\hline 18 & 3,35 & 2,73 \\
\hline 19 & 3,70 & 2,97 \\
\hline 20 & 1,35 & 1,17 \\
\hline 21 & 3,10 & 3,50 \\
\hline 22 & 1,90 & 3,93 \\
\hline 23 & 3,05 & 3,90 \\
\hline 24 & 2,90 & 3,43 \\
\hline 25 & 3,85 & 3,57 \\
\hline 26 & 3,65 & 4,43 \\
\hline 27 & 3,75 & 4,13 \\
\hline 28 & 2,40 & 2,60 \\
\hline 29 & 2,55 & 2,27 \\
\hline 30 & 2,95 & 3,07 \\
\hline
\end{tabular}

Çook - Kress - Seiford modeli ile ürün kalitesi etkinlik analizi yapmak için 2 nolu formülasyonda yer verilen model, her bir karar verme birimi için ayrı ayrı yazılarak tüm makine imalat işletmeleri için ürün kalitesi etkinlik skorları hesaplanmıştır. Etkin çıkan karar verme birimlerinin kendi içerisinde etkinlik skorlarına göre sıralanabilmesi için, Andersen ve Petersen (1993) tarafından geliştirilen süper etkinlik modeli uygulanmıştır. Süper etkinlik modelinde, veri zarflama analizi modelinde yer alan ve etkinlik skorlarının maksimum bir olmasını sağlayan, “ 3 ” nolu formülde yer alan kısıt, etkinlik analizi yapılan karar verme birimi için oluşturulan modelde yer almaz.

$$
\sum_{r=1}^{s} u_{r} y_{r j}^{L}+\sum_{h=1}^{w} u_{r} y_{h j}-\sum_{i=1}^{m} v_{i} x_{i j}^{L}+\sum_{b=1}^{f} v_{i} x_{b j} \leq 0
$$

Cook - Kress - Seiford modeli ile elde edilen ürün kalitesi etkinlik değerleri ve bu etkinlik değerlerine göre makine imalat işletmelerinin ürün kalitesi etkinlik sıralamaları Tablo 7'de verilmiştir. Etkinlik değeri bir olarak görünen işletmeler için parantez içerisinde verilen değer, etkin işletmeler için hesaplanan süper etkinlik skorudur.

Tablo 7. Cook - Kress - Seiford Modeline Göre Etkinlik Skoru ve Etkinlik Sıralaması

\begin{tabular}{|c|c|c|}
\hline İŞLETME NO & ETKİNLİK DEĞERİ & SIRALAMA \\
\hline 1 & 0,397 & 24 \\
\hline 2 & 0,531 & 15 \\
\hline 3 & 0,898 & 6 \\
\hline 4 & 0,369 & 29 \\
\hline 5 & 0,423 & 20 \\
\hline 6 & 0,479 & 17 \\
\hline 7 & 0,702 & 7 \\
\hline 8 & 0,465 & 19 \\
\hline 9 & 0,468 & 18 \\
\hline 10 & 0,598 & 13 \\
\hline 11 & 0,680 & 9 \\
\hline 12 & 1 & 5 \\
\hline 13 & 0,410 & 22 \\
\hline 14 & 0,416 & 21 \\
\hline 15 & 0,382 & 26 \\
\hline 16 & $1(3,86)$ & 1 \\
\hline 17 & 0,629 & 12 \\
\hline 18 & 0,406 & 23 \\
\hline 19 & 0,372 & 27 \\
\hline 20 & $1(2,282)$ & 2 \\
\hline 21 & $1(1,032)$ & 3 \\
\hline 22 & $1(0,007)$ & 4 \\
\hline 23 & 0,685 & 8 \\
\hline 24 & 0,652 & 10 \\
\hline 25 & 0,359 & 30 \\
\hline 26 & 0,371 & 28 \\
\hline 27 & 0,385 & 25 \\
\hline 28 & 0,639 & 11 \\
\hline 29 & 0,537 & 14 \\
\hline 30 & 0,482 & 16 \\
\hline
\end{tabular}




\section{Sonuç}

Makine imalat işletmelerinin ürün kalitesi bakımından sektörlerinde bulundukları noktanın ve de ürün kalitesinin iyileştirilmesi için hangi boyutların iyileştirilmesi gerektiğinin belirlenmesi bu çalışmanın ana amacıdır. Garvin tarafından ortaya konulan ürün kalitesi boyutları sinıflandırmasında, hem objektif değerlendirmelere göre kesin değeri bilinen, sayısal verilerle ifade edilen, hem de sübjektif değerlendirmelere dayalı olarak ifade edilen kalite boyutları yer almaktadır. Bu nedenle sektördeki ișletmelerin ürün kalitesi bakımından hangi seviyede olduklarının değerlendirilmesi amaçlı olarak yapılan göreli etkinlik analizi için "Veri Zarflama Analizi" (VZA) yöntemi yerine bulanık veri zarflama analizi (BVZA) yöntemi kullanılmıştır.

Ürün kalitesi etkinlik analizi yapılan Cook - Kress Seiford modeli kalite gibi dilsel değiş̧kenlerle, kişisel yargılara dayalı olarak değerlendirilen girdi - çıktı değişkenlerinin söz konusu olduğu alanlar için uygun bir modeldir. Bu nedenle göreli etkinlik analizi için söz konusu model uygulanmıştır. Cook - Kress - Seiford modeli ile elde edilen sonuçlar incelendiğinde sıralı çıktı değerleri bakımından maksimum değere sahip olan 5 işletmenin etkin olarak bulunduğu görülmektedir. Aynı zamanda sıralı çıktı değerleri bakımından maksimum değere sahip olan işletmelerin etkinlik değerleri diğer modellerde aynı işletmeler için elde edilen etkinlik değerlerinden yüksek görünmektedir. Bunun nedeni, Cook - Kress - Seiford modelinde sıralı çıktı değerlerinin maksimum olduğu karar birimleri için, sıralı çıtı değerlerinin yüksek ağırlık değerlerine sahip olmaları olarak ifade edilebilir.

Karar verme birimi ve girdi, çıktı sayısının fazla olması durumunda doğrusal programlama modelleri şekline dönüştürülen VZA modelleri daha karmaşı hale gelmekte ve uygulanması zorlaşmaktadır. Bu durumlar için VZA uygulamalarını kolaylaştırmak adına kullanılan çok sayıda bilgisayar uygulaması mevcuttur. Ancak bulanık BVZA modelleri için sıralı ve sınırlandırılmış verilerin tanımlanarak göreli etkinlik analizi yapılabileceği bir program söz konusu değildir. Karar verme birimi ve girdi çıktı sayılarına göre yüzlerce karar değişkeni ve kısıt gerektiren modellerin oluşturulması ve çözülmesi uzun zaman ve uğraş gerektirmektedir.
VZA yöntemi etkinlik analizi yapılan karar verme biriminin diğer karar birimlerine göre konumunu belirlemenin yanı sıra, etkinliğe ulaşmak için hangi girdi ve çıtıları ne ölçüde iyileştirmesi gerektiğinin belirlenmesini sağlamaktadır. Bu özelliğinden dolayı literatürde bazı çalışmalarda VZA yöntemi işletmelerin en iyi benchmarking partnerini seçmelerine yardımcı olan bir yöntem olarak da kullanılmıştır. Kalite, insan kaynakları, halkla ilişkiler gibi hem objektif verilere dayalı olarak hem de sübjektif yargılara dayalı olarak değerlendirilen alanlarla ilgili yapılacak kıyaslama faaliyetlerinde BVZA yönteminin kullanılması mümkündür. Göreli etkinlik analizi için bulanık veri zarflama analizi modellerinin kullanılması, sübjektif ve sayısal değerlerle ifade edilemeyen girdi çıtı değişkenlerinin kullanımını mümkün kılar. Bununla birlikte, göreli etkinlik analizinin daha geniş alanlarda uygulanmasına da olanak sağlar.

Yukarıda ifade edildiği gibi, VZA yönteminin en önemli avantajlarından birisi etkin olmayan karar verme birimlerinin etkinliğe ulaşması için girdi ve çıktı değişkenlerini hangi oranda iyileştirmeleri gerektiğinin belirlenmesidir. Etkin olmayan bir karar verme birimi için referans grubunda yer alan etkin karar verme birimlerinin girdi ve çıtı değişkenlerinin değerleri baz alınarak iyileştirme oranları hesaplanmaktadır. BVZA yönteminde ise etkin olmayan karar verme birimleri için değişkeni ve referans grupları belirlenebilmektedir. Ancak, sıralı ve sınırlandırılmış veriler şeklinde ifade edilen girdi ve çıktı değişkenleri için iyileştirme oranının hesaplanması ancak söz konusu değişkenlerin kesin değerlere dönüştürülmesi ile mümkün olabilmektedir. Sıralı ve sınırlandırılmış verilerin kesin değere dönüştürülmesinin mümkün olmadığ 1 durumlar için iyileştirme oranlarının hesaplanabileceği kanıtlanmış bir yöntemin geliştirilmesinin faydalı olabileceği öngörülmektedir.

BVZA ile ürün kalitesi etkinlik analizi yapmak için girdi ve çıktı değişkenlerine ilişkin veriler yukarıda da ifade edildiği gibi hazırlanan ölçeğin firma yöneticileri tarafından doldurulması ile elde edilmiştir. İşletmeler, sektörleri içerisinde herhangi bir konuda BVZA ve benzeri bir yöntemle etkinlik analizi yapabilmek için kendi işletmeleri ve rakipleri ile ilgili girdi ve çıktı verilerine ihtiyaç duyacaktır. Bilginin öneminin her geçen gün arttığı ve endüstriyel bilgiye ulaşmanın giderek zorlaştığı bir dönemde rakiplerle ilgili 
veri toplamak ve bilgi sahibi olmak oldukça zordur. $\mathrm{Bu}$ konuda işletmelerin bu çalışmada olduğu gibi bir ölçek kullanarak kendi işletmelerini ve rakiplerini bu ölçeğe göre değerlendirmelerinin mümkün olabileceği düşünülmektedir. Bu çalışmada etkinlik analizi yapılan sektör ve üretilen ürün göz önüne alınarak geliştirilen bir ölçek kullanılmıştır. Etkinlik analizi yapılacak olan sektör, üretilen ürün ya da hizmetin niteliği ve değerlendirme yapılan konuya bağlı olarak farklı ölçeklerin kullanılması mümkündür.

\section{Kaynakça}

Ackaradejruangsri, P. (2013). The Effects of Product Quality Attributes on Thai Consumers Buying Decision. Ritsumeikan Journal of Asia Pacific Studies. 33, $14-24$

Agarwal, S. (2014). Efficiency Measure by Fuzzy Data Envelopment Analysis Model. Fuzzy Information and Engineering. 6, 59-70. doi:10.1016/j. fiae.2014.06.005

Akyüz, K. C., Çamur, G., Yıldırım, İ. (2015). Mobilya ve Levha Sektöründe Veri Zarflama Analizi Yard1mı İle Etkinlik Ölçümü. Türkiye Ormancıllk Dergisi. 16 (1), 50-59

Arnheiter, E. D., Harren, H. (2006). Quality Management in a Moduler World. The TQM Magazine. 18 (1): 87-96. doi:10.1108/09544780610637712

Andersen, P., Petersen, N. C. (1993). A Procedure for Ranking Efficient Units in Data Envelopment Analysis. Management Science. 39 (10): 1261-1264

Azadeh, A., Fam, M. I., Nazifkar, N. (2010). The Evaluation and Improvement of Safety Behaviours Among Contractors of a Large Steel Manufacturing Company by Fuzzy Data Envelopment Analysis. Journal of the Chinese Institute of Engineers. 33 (6), 823-832. doi:10.1080/02533839.2010.9671672

Boussofiane, A., Dyson, R.G., Thanassoulis E. (1991). Applied Data Envelopment Analysis. European Journal of Operational Research. 52 (1), 1-15. doi: 10.1016/0377-2217(91)90331-O
Chiarini, A. (2015). Effect of ISO 9001 NonComformity Processon Cost of Poor Quality in Capital Intensive Sectors. International Journal of $\mathrm{Qu}$ ality and Reliability Management. 32 (2), 144-155.

Chorafas, D.N. (2013). Quality Control Application. Londra: Springer Verlag

Cook, W. D., Kress, M., Seiford, L. M. (1996). Data Envelopment Analysis in the Precense of Both Quantitative and Qualitative Factors. Journal of the Operational Research Society. 47, 945-953. doi: $10.2307 / 3010140$

Despotis, D. K., Smirlis, Y. G. (2002). Continupus Optimization Data Envelopment Analysis With Imprecise Data. European Journal of Operational Research. 140, 24-36

Dyson, R.G., Allen, R., camanho, A.S., Podinovski, V.V., Sarrico, C.S., Shale, E.A. (2001). Pitfalls and Protocals in DEA. European Journal of Operational Research, 132, 245-259. 10.1016/S03772217(00)00149-1

Garvin, D.A. (1984). What Does "Product Quality" Really Mean?. Sloan Management Review. 26 (1), 25-43

Gildea, L. F. (1991). The Relationship Between Elements of Quality, Dimensions of Culture and Performance in Manufacturing Companies Located in Inland Northwest. (Yayınlanmamış Doktora Tezi). Faculty of the School of Conzaga University, Washington

Guo, P., Tanaka, H. (2001). Fuzzy DEA: A Perceptial Evaluation Model. Fuzzy Sets and Systems. 119, 149-160. doi: 10.1016/S0165-0114(99)00106-2

Güngör, İ., Oruç, K. O. (2009). Bulanık Veri Zarflama Analizi Modellerinin Karşılaştırılması: Sıralı ve S1nırlandırılmış Bulanık Veriler İçin. Alanya İşletme Fakültesi Dergisi. 1 (1), 17-32

Harrington, J. (1999). Performance Improvement: A Total Poor Quality Cost System. The TQM Magazine. 11 (4), 221-230 
Kenyon, G. N. ve Sen, K. C. (2015). The Perception of Quality. Londra: Springer-Verlag

Kianpour, K., Jusoh, A., Asghari M. (2014). Environmentally Friendly as a New Dimension of Product Quality. International Journal of Quality \& Reliability Management. 31 (5), 547-565. doi: 10.1108/ IJQRM-06-2012-0079

Mahmood, S., Ahmed, S. M., Pahthi, K., Kureshi, N. I. (2014). Determining the Cost of Poor Quality and Its Impact on Productivity and Profitability. Build Environment Project and Asset Management. 4 (3): 296-311. doi: 10.1108/BEPAM-09-2013-0034

Marbini, A. H., Saati, S., Tavana M. (2010). An Ideal Seeking Fuzzy Data Envelopment Analysis Framework. Applied Soft Computing. 10, 1062-1070. doi: /10.1016/j.asoc.2009.12.031

Oruç, K. O. (2008). Veri Zarflama Analizi ile Bulanık Ortamda Etkinlik Ölçümleri ve Üniversitelerde Bir Uygulama. (Yayınlanmamış Doktora Tezi). Süleyman Demirel Üniversitesi/Sosyal Bilimler Enstitüsü, Isparta
Oruç, K. O., Güngör, İ., Demiral, M. F. (2009). Üniversitelerin Etkinlik Ölçümünde Bulanık Veri Zarflama Analizi Uygulaması. Selçuk Üniversitesi Sosyal Bilimler Enstitüsü Dergisi. 22, 279-294

Özdemir, A. (2016). Yönetim Biliminde İleri Araştırma Yöntemleri ve Uygulamalar. İstanbul: Beta Basım

Shukla, M. K., Agrawal P. C. (2012). Impact of Cost of Poor Quality in Indian Automobile Sector. International Journal of Engineering Research and Applications. 2 (2), 1297-1302. doi: 10.1504/IJQET.2014.059842

Tarım, A. (2001. Veri Zarflama Analizi Matematiksel Programlama Tabanlı Göreli Etkinlik Ölçüm Yaklaşımı. Ankara. Sayıştay

Tütek, H., Gümüşoğlu Ş. ve Özdemir, A. (2012). Saylsal Yöntemler Yönetsel Yaklaşım. İstanbul. Beta

Waller, M. A., Ahire, W.S. (1996). Management Perception of the Link Between Product Quality and Customers View of Product Quality. İnternational Journal of Operations \& Production Management. Say1: 6 (9), 23-33. 